\title{
Correction to: Insight into Practical Teaching in Rural Planning in Colleges Based on the "Rural Innovation Workshop"
}

\section{Yinglu Huang ${ }^{1,2} \cdot$ Jiarui Zhang ${ }^{2,3}$ (D) Xiaolei Sang ${ }^{1,4} \cdot$ Haifeng Ou ${ }^{1}$}

Published online: 12 April 2021

๑) Springer Science+Business Media, LLC, part of Springer Nature 2021

\section{Correction to: Systemic Practice and Action Research \\ https://doi.org/10.1007/s11213-021-09561-0}

The original version of this article unfortunately contained some mistakes. Author's affiliations and corresponding author assignments were corrected.

In addition, Authors' sure names and given names were interchanged. It must be read as Yinglu Huang, Jiarui Zhang, Xiaolei Sang and Haifeng Ou.

The original paper has been updated.

Publisher's Note Springer Nature remains neutral with regard to jurisdictional claims in published maps and institutional affiliations.

The original article can be found online at https://doi.org/10.1007/s11213-021-09561-0.

\section{Jiarui Zhang}

zhang0057@gdut.edu.cn

1 School of Architecture, Huaqiao University, Xiamen 361021, China

2 National Taipei University, Taipei, Taiwan 237303

3 Guangdong University of Technology, Guang Zhou, Guangdong 510006, China

4 National Taipei University of Technology, Taipei, Taiwan 10608 